\title{
Die Welt wird wieder flach
}

\section{Jürg Kesselring}

Prof. Dr. med., Chefarzt Neurologie \& Neurorehabilitation, Rehabilitationszentrum Valens, Mitglied FMH

Ich stelle mir vor, wie sich Leute gefühlt haben müssen, wenn sie erstmals mit Flossen und Booten aufs Meer fuhren, wenn sie durch die Savannen und Ebenen streiften, um zu Nahrungsmitteln zu gelangen, die sie vielleicht früher gar nicht gekannt hatten, wie sie anfingen Handel zu treiben und damit Kontakt zu fremden Leuten finden durften, wie sie wieder heimkehrten, um zu berichten, was sie gesehen haben: wunderbar! Die Philosophen kamen zusammen, spazierten auf und ab im Austausch der Gedanken, die Lehrer nahmen ihre Schüler an der Hand und zeigten ihnen alles, was sie wussten und konnten, luden sie ein und leiteten sie an, zu lernen,

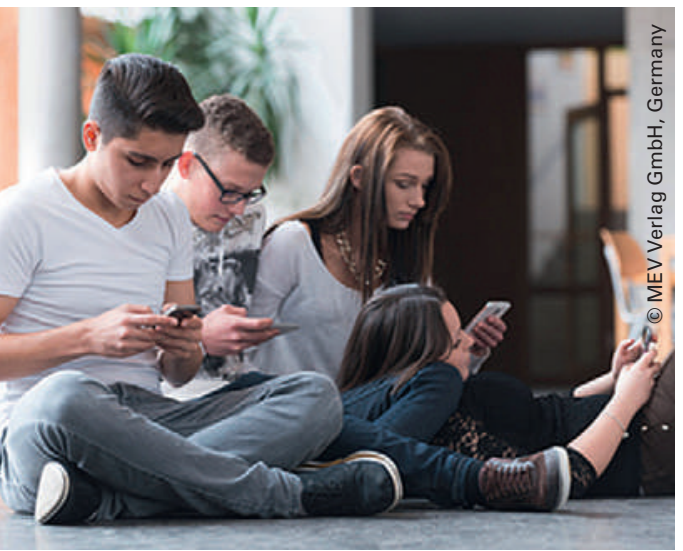

Kommunikation auf dem Schulhof. noch mehr zu wissen als sie selbst und waren glücklich, wenn ihre Schüler mehr wussten als sie selbst und auch dies wieder mit ihnen teilten. Da war Austausch ein Gut.

Dann kamen andere, die die Welt nur in ihrem Kopf erlebt hatten, die vielleicht bestenfalls einmal auf eine Zinne gestiegen waren und behaupteten, die Welt zu kennen, von ihrem Anfang bis zu ihrem Ende, und sie dann auch richten würden mit allem, was darin kreuche und fleuche, die in ihren Wüstendörfern nicht einmal das Meer gesehen hatten, nicht die Alpen, nicht die Anden und schon gar nicht den Himalaya, und ihre Mit-Menschen mit Staubkörnern und Würmern verglichen, so dass diese nur noch zitternd und zagend über die Erde huschten und schlichen. Die solch grausame Metaphern erfanden wie dass es die höchste Form von Liebe sei, wenn man seinen Sohn schlachten liesse und auf seine bange Frage nach dem «Warum?» einfach schwiege ... Dunkel wurde es und flach waren die Gedanken, man berief sich auf die Rechthaber und blieb in dürftigen Hütten und Häusern, zog allenfalls im Krieg über Land, um Gegner zu vernichten.

Später gab es - unvermittelt? - grosszügige Fürsten und Mäzene, die an ihre Höfe die Gescheitesten einluden, zu lernen und zu lehren, zu schreiben und zu lesen, selbst künstlerisch tätig zu werden und ihr Wissen und Können öffentlich darzustellen, damit alle davon profitieren konnten. Es war eine Wiedergeburt, eine Renaissance - ob nun in Florenz, in Oxford und Cambridge, an französischen Höfen ... Man lernte Sprachen, um Fremde zu verstehen, und gewann Freude am Wunder der Sprache. Die Mutigsten bauten Schiffe und fuhren aufs Meer, entdeckten Kontinente, sammelten und brachten heim, was sie gesehen und aufgenommen hatten, tauschten aus mit anderen, die Ähnliches in anderen Gebieten erlebt hatten: Es war akademisches Leben. Die Mutigen und Kundigen wurden die Bescheidensten, denn sie wussten, dass mit jeder gelösten Frage Tausende neuer Fragen sich auftaten, wie wenn eine Kugel des Wissens in einem Meer des Unwissens schwimmen würde und mit jeder Vergrösserung der Kugel und Erweiterung des Wissens die Zahl der Berührungspunkte mit dem Unwissen sich vermehrte. Und sie erkannten: «Am gefährlichsten sind die Weltanschauungen derjenigen, die die Welt gar nie angeschaut haben.» Sie waren zwar bereit, im äusseren Leben Gefahren auf sich zu nehmen, aber sie wollten bezüglich Weltanschauung nicht so gefährlich leben.

Es war Aufbruch, es war Aufklärung, es war Wissenschaft im Austausch - Lebensfreude.

Und dann kam wieder die Verflachung: ein flaches, knapp $1 \mathrm{dm}^{2}$ grosses Kästchen, handlich mit sich zu führen, 4-Zahlen-Code, Plastikoberfläche, auf der die Jungen im Schulhof sich «Riesentitten» hineinziehen können, vielleicht noch mit dem gespreizten Gynäkologengriff das Ganze aufzoomen, enlargen, aber es bleibt flach und aus Plastik und duftet nicht. Wenn man im tiefsten Süd-Sudan den ungestörten Nachthimmel betrachtet und die fremde Konstellation des Grossen Bären bestaunt, so kommt mit dem letzten Rest von Internet ein riesenhafter, freundlicher Kollege daher, selbst ebenso schwarz wie die Nacht, der mich darauf aufmerksam macht, wie die Welt doch viel einfacher sei, als ich dies erträume: Einfach Google Sky Maps downloaden, hinklicken, wo der Grosse Wagen ist und dann einfach das iPad umdrehen ... Die Landung eines Flugzeuges - wo und woher auch immer -, ist gleichbedeutend damit, dass alle Passagiere gleichzeitig ihr Handy aus der Tasche ziehen und irgendwohin melden, dass man gelandet sei. Standortbestimmung. Vernetzung der Bewegung wildfremder Leute zum Standard. Emoticon :-) oder :-( als Ausdruck von Gefühlen. Auch die letzten literarischen Erzeugnisse wie Einkaufslisten kommen als Apps daher. Es wird die Globalisierung der Gleichgültigkeit, Plastikflächen werden realer als lebendige Rundungen, Erkundungen ersetzt durch Download. 